J. AMER. SOC. HORT. SCI. 118(1):29-35. 1993.

\title{
Chilling and Heating Model for Pecan Budbreak
}

\author{
Darrell Sparks ${ }^{1}$ \\ Department of Horticulture, University of Georgia, Athens, GA 30602
}

Additional index words. Carya illinoinensis, dormancy, degree days, rest

Abstract. Chilling and heating effects on budbreak of pecan [Carya illinoinensis (Wangenh.) K. Koch] trees were examined by linear regression analyses from experimental data and from records of budbreak dates over a wide geographic range. The results demonstrate that budbreak in pecan is under the interactive control of heating and of chilling. Heat required for budbreak varies inversely with chill accumulation, and budbreak may occur with no chilling once sufficient heat accumulates. Variability in budbreak increases dramatically when there are fewer than $\approx 100$ chilling degree days. Heating degree days with daily minima $<2.2 \mathrm{C}$ are inefficient; $3.9 \mathrm{C}$ is the most efficient heating and chilling base. At base 3.9C and the daily minimum heating temperature of $2.2 \mathrm{C}$, heating degree days required for budbreak of a composite of cultivars can be predicted from chilling degree days over a wide geographic range by the relationship, $\log Y=2.7190-0.0216 \sqrt{X}$.

Chilling and heating requirements for budbreak in pecan have not been clearly defined. Pecan was assumed to have a rest period based on staggered or irregular budbreak observed following mild winters (Finch and Van Horn, 1939; Gammon and Sherman, 1972; Waite, 1925). From response of pecan stem cuttings, McEachern et al. (1978) concluded that 'Desirable' and 'Mahan', two early budbreaking cultivars, have a chilling requirement of $500 \mathrm{~h}$, while 'Stuart', a late-breaking cultivar, has a chilling requirement of $600 \mathrm{~h}<7.2 \mathrm{C}$. Amling and Amling (1980) also found stem cuttings of 'Stuart' to have a higher chilling requirement than those of 'Desirable', 'Mahan', and 'Success' but suggested that actual chilling requirements vary with conditions existing in the fall. They proposed that if trees are exposed to fall temperatures of $\leq 1.2 \mathrm{C}$, rest intensity increases. Thus, in regions of mild falls and winters, most pecan cultivars develop a low rest intensity, giving pecan the appearance of having little or no chilling requirement. Amling and Amling further proposed that rest intensity, is enhanced if pecan trees have green leaves or fruit when exposed to chilling temperatures in the fall. Such trees develop a higher rest intensity than trees without leaves or fruit and symptoms of delayed budbreak occur if rest intensity is not reduced by subsequent low temperature. In a later paper, Amling and Amling (1983) concluded that low-temperature exposure was necessary for pistillate flower initiation; however, Finch and Van Horn (1939) found no correlation between irregular budbreak and nut yield.

From a survey of pecans growing in central and south Florida, Arnold (1971) suggested the date of budbreak is regulated more by a heat requirement than by a chilling requirement; however, he concluded from Waite (1925) and Finch and Van Horn (1939) that the pecan has a low chilling requirement. Wolstenholme (1970) suggested that pecan budbreak depends on the interaction between chilling in the winter and heating in the spring but set no definitive parameters. The objectives of this study were to experimentally determine the chilling and heating effect on the date of pecan budbreak and determine whether a mathematical model could be developed to reliably predict budbreak over the wide climatic range in which pecan is grown.

\footnotetext{
Received for publication 3 Apr. 1992. Accepted for publication 1 July 1992. I thank Gloria Belvan for the long, tedious calculations. The cost of publishing this paper was defrayed in part by the payment of page charges. Under postal regulations, this paper therefore must be hereby marked advertisement solely to indicate this fact.

${ }^{1}$ Professor of Horticulture.
}

\section{Materials and Methods}

Expression of chilling and heating. In this paper, chilling is expressed either as hours of chilling or as chilling degree days; heating is expressed as heating degree days. One degree day was accumulated for each degree that the daily mean ambient temperature was below or above a given base. The mean is the average of the maximum and minimum for the day. The degree day is referred to as a chilling degree day if the daily average is below the base and as a heating degree day if the mean is above the base.

Chilling experiment. Three-year-old own-rooted 'Stuart' pecan trees originally propagated as air layers from adult trees (Sparks and Chapman, 1970) were used. The trees retained the adult characteristics of pecan (Romberg, 1944). Trees were maintained for two growing seasons in the greenhouse in 47liter pots filled with 1 soil : 1 sand : 1 peat mixture (by volume). During the first year in the greenhouse, nights were $\approx 21 \mathrm{C}$ from 1 May until mid-November, and days ranged from $\approx 27$ to $35 \mathrm{C}$. From mid-November through January, the greenhouse was maintained at $\geq 7.2 \mathrm{C}$. Defoliation occurred during this interval. During the summer months of the 2nd year, temperature ranges were similar to those of the previous year; however, winter temperatures were maintained at $\geq 7.2 \mathrm{C}$ only until $7 \mathrm{Dec}$., the date of initiation of the experiment.

On 7 Dec., 30 trees were divided into five groups of six trees each. One group served as the unchilled control and the other four groups were chilled in the dark at $7.2 \pm 1.0 \mathrm{C}$ for 200 , 400,600 , or $800 \mathrm{~h}$. The unchilled trees remained in the greenhouse and the chilled trees were transferred back to the greenhouse following their respective chilling treatments. Beginning 8 Dec., night temperature was set at $21 \mathrm{C}$ and day temperature at $32 \mathrm{C}$. Budbreak was calculated as average time from 8 Dec. to occurrence of budbreak for all l-year-old branches on each tree. A bud was scored as broken when bud development was at stage IV; that is, the inner bud scales were broken and the bud had expanded slightly beyond the inner bud scale (Wetzstein and Sparks, 1983). Budbreak was scored irrespectively of bud position (terminal or lateral) on the branch. Greenhouse temperature was recorded as maximum and minimum per $24 \mathrm{~h}$. Heating degree days were calculated from base $7.2 \mathrm{C}$ and accumulated from end of chilling to budbreak. Trees (six singletree replications) were chilled in a completely randomized design. Greenhouse evaluation of treatments was in a randomized complete block.

$\overline{\text { Abbreviations: }}$ SEE, standard error of estimate. 
Heating experiment. Twenty pecan trees each of 'Pawnee' and 'Stuart' were planted in Feb. 1987 into 22-liter pots filled with 1 soil : 1 sand : 1 peat mixture (by volume) and kept in a greenhouse maintained above freezing. During the growing seasons of 1987 and 1988, the trees were maintained outdoors. During Winter 1987-88, the trees were kept in a greenhouse with minimum temperature above freezing. On 15 Oct. 1988, the trees were planted in the field with the pots intact. On 16 Mar. 1989, differential temperature regimes were established by transferring half of the trees of each cultivar to a greenhouse and maintaining them in the greenhouse until after budbreak. The other trees were left in the field. The greenhouse was $\approx 21 \mathrm{C}$ at night with a maximum of $\approx 32 \mathrm{C}$ during the day. Thus, treatments were two cultivars and two temperature regimes. Each treatment combination was replicated 10 times. The data were analyzed as a $2 \times 2$ factorial in a randomized complete block.

Temperature was recorded in field and greenhouse as maximum and minimum per $24 \mathrm{~h}$. Chilling degree days were calculated from base $7.2 \mathrm{C}$ and accumulated from $1 \mathrm{Dec}$. through February. Heating degree days were calculated from the same base and accumulated from 1 Feb. to budbreak. Budbreak was determined as the time when buds had broken on at least $50 \%$ of the 1-year-old branches on each tree.

Correlative analyses of budbreak with chilling and heating. Budbreak data were obtained from the literature and unpublished sources (Table 1). The cultivars were not common to all locations although some were at certain locations. Only data for southern cultivars were used, except at Lincoln, Neb., where all cultivars were northern. When selecting budbreak data, care was taken to exclude those data that were preceded by late spring freezes (two cases), data in which a freeze occurred during the period of budbreak (one case), data collected during a drought (one case) or from trees with zinc deficiency (one case).

Average budbreak date for all cultivars at each location was expressed as Julian days. Variability in budbreak among cultivars at each location was expressed as coefficient of variation (cv). Chilling degree days were accumulated from 1 Dec. through February and heating degree days from 1 Feb. to average budbreak date. Some chilling $(8 \% \pm 7 \%$ of the November-February accumulation, base $7.2 \mathrm{C}$ ) occurred in November at all locations except South Africa. November chilling was excluded because its inclusion increased the standard error of estimate (SEE) for the relationship between heat accumulated to bud- break and chill accumulation. Some heating (14\% $\pm 12 \%$ of the January to budbreak accumulation, base 7.2C) occurred in January at all locations except for Nebraska in 1988 and 1989. January heating caused an increase in the SEE and was excluded. Dates for Roodeplaat, South Africa, were converted to Northern Hemisphere equivalent time. Temperatures, recorded as maximum and minimum per $24 \mathrm{~h}$, were taken as recorded by the National Oceanic and Atmospheric Administration from stations nearest to the pecan orchards. Exceptions were Watkinsville, Ga., where temperatures were recorded in the orchard, and Roodeplaat, where temperatures are for the Roodeplaat Experimental Station (data supplied by J.T. Meynhardt). At other locations, the stations were Visalia, Calif.; Griffin, Ga.; Stoneville, Miss.; Shreveport, La.; Lincoln, Neb.; and Bristow and Stillwater, Okla.

Chilling and heating degree days were calculated for base temperatures of $2.2,2.8,3.9,4.4,5.0,5.6,6.1,6.7$, and 7.2C. The correlation of heating degree days to budbreak date with chilling degree days was calculated for each base to determine the most suitable base temperature. In the next step, the correlations were recalculated for the same bases with restrictions placed on the daily minimum temperature used to calculate heating degree days. For each base, the correlation was first calculated by excluding days on which the minimum reached $-2.2 \mathrm{C}$ and below, followed by iterative deletion of minima up to 3.9C. The deletion of certain days with low temperatures was justified under the hypothesis that a low night temperature may negate or minimize the heating effect of day temperature. Such an effect would be analogous to negation of chilling by a high day temperature (Couvillon and Erez, 1985; Erez et al., 1979a, 1979b). In the final step, the base temperature and the minimum temperature used for calculation of heating degree days that produced the best predictive equation were recalculated. In this case, restrictions were placed on the daily minimum temperature used to calculate chilling degree days. The equation was first calculated by excluding days on which the minimum chilling temperature was $-21 \mathrm{C}$ or lower, followed by iterative deletion of increasing minimum temperatures until a trend became evident. Low daily minimum temperatures were progressively deleted because data for continuous chilled peach [Prunus persica (L.) Batsch.] trees show that chilling efficiency decreased as temperature decreased from 8 to 0C (Erez and Couvillon, 1987).

The model was not specifically adjusted for chilling negation

Table 1. Source of budbreak data by location, year(s), number of cultivars, and references.

\begin{tabular}{|c|c|c|c|}
\hline Location & Years & $\begin{array}{c}\begin{array}{c}\text { Cultivars } \\
\text { (no.) }\end{array} \\
\end{array}$ & Source \\
\hline$\overline{\text { Visalia, Calif. }}$ & 1982-86, 1988 & 25 & $\begin{array}{l}\text { Sibbett et al., 1988, original data } \\
\text { from G.S. Sibbett }\end{array}$ \\
\hline Stoneville, Miss. & 1986 & 10 & V.R. Calcote, unpublished data \\
\hline Shreveport, La. & 1977 & 14 & O'Barr and Rachal, 1987 \\
\hline Griffin, Ga. & 1916 & & Stuckey, 1916 \\
\hline Watkinsville, Ga. & 1989-91 & $\begin{array}{c}7(1989-90) \\
18(1991)\end{array}$ & D. Sparks, unpublished data \\
\hline Stillwater, Okla. & $\begin{array}{l}1972 \\
1976\end{array}$ & $\begin{array}{l}11 \\
13\end{array}$ & $\begin{array}{c}\text { Boethel et al., } 1976 \\
\text { Burke and Hinrichs, } 1976\end{array}$ \\
\hline Sparks, Okla. & 1976 & & Burke and Hinrichs, 1976 \\
\hline Lincoln, Neb. & 1987-89 & $\begin{array}{l}16(1987) \\
31(1988) \\
35(1989)\end{array}$ & $\begin{array}{c}\text { Nelson et al., } 1987 \\
\text { Nelson et al., } 1988 \\
\text { Gustafson and Morrissey, } 1989\end{array}$ \\
\hline $\begin{array}{l}\text { Roodeplaat, } \\
\text { South Africa }\end{array}$ & $1981-84$ & 5 & Haulik and Holtzhausen, 1987 \\
\hline
\end{tabular}


from intermittent high temperature. Negation in peach occurred only in the first half of the chilling cycle and then only after a 12-day exposure to 23C (Couvillon and Erez, 1985). Such a long exposure of pecan to this temperature during early chilling (December) is unlikely. Interspersion of high temperature during chilling is most likely to occur during the latter portion of the chilling season. High temperature interspersion during this period actually promotes budbreak (Erez and Couvillon, 1987). In the model for pecan budbreak, this potential promotive effect is included within the heating cycle, 1 Feb. to budbreak.

\section{Results}

Chilling experiment. Own-rooted 'Quarts broke buds without chilling. Chilling decreased days to budbreak, but the decrease was less as chilling accumulated (Fig. 1). The relationship is described by $\log \mathrm{Y}=\mathrm{a}-\mathrm{b} \sqrt{\mathrm{X}}$, where $\mathrm{Y}$ is days to budbreak and $\mathrm{X}$ is number of chilling hours. Heat accumulation until budbreak of 'Stuart' trees was inversely related to chill accumulation (Fig. 2) and also followed $\log Y=a-b \sqrt{X}$. This mathematical relationship, $\log Y=a-b \sqrt{X}$, between heat accumulation and chill accumulation to achieve $50 \%$ budbreak was used to develop a field model for budbreak.

Heating experiment. Trees transferred to the greenhouse broke buds 7 days earlier than those maintained under field conditions (Table 2). However, on the basis of heat accumulation, trees broke buds after accumulation of the same amount of heat; that is, $\approx 237$ degree days. These data show that, at a given chilling level, pecans have a heat requirement for budbreak.

Correlative analyses of budbreak with chilling and heating. Under field conditions and across geographical locations and years, heat accumulation to budbreak was inversely related to the amount of chilling received during the preceding winter (Table 3). Based on SEE, the best relationship between heat accumulation to budbreak and chilling occurred at base temperatures 3.9 and $4.4 \mathrm{C}$. The traditional temperature base of 7.2C produced the second poorest relationship.

With all base temperatures, the daily minimum temperature used to calculate heating influenced the precision of the relationship between heat accumulation to budbreak and chilling

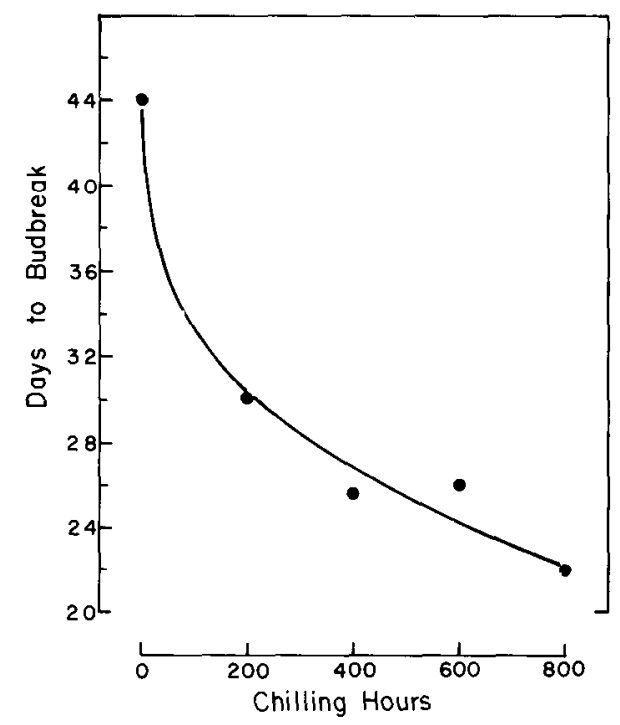

Fig. 1. Time of budbreak of own-rooted 'Stuart' pecan trees as influenced by chilling hours at $7.2 \mathrm{C}$. The relationship is described by $\log \mathrm{Y}=1.6341-0.0102 \sqrt{\mathrm{X}}$. Regression coefficient is signif-

J. Amer. Soc. Hort. Sci. 118(1):29-35. 1993.

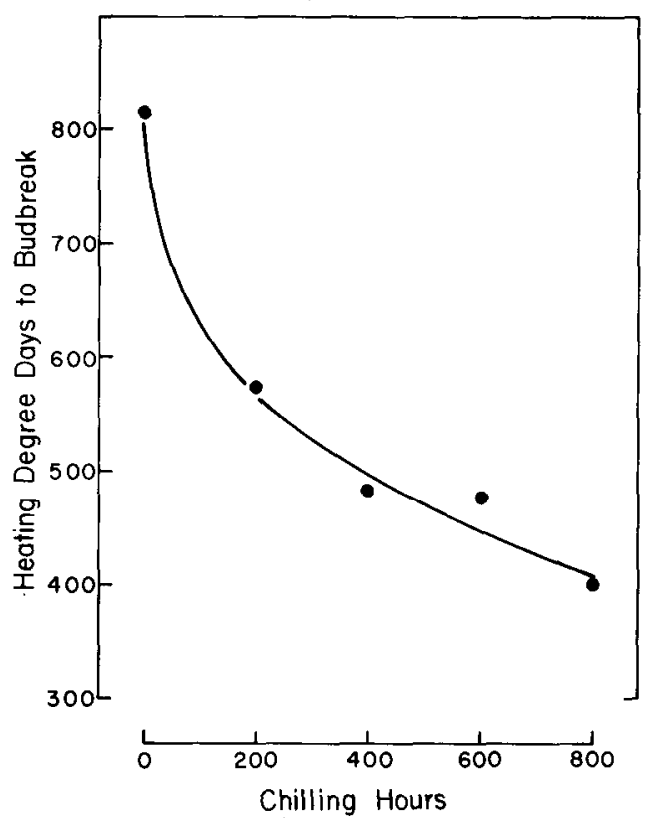

Fig. 2. Heating degree days accumulated until budbreak of ownrooted 'Stuart' pecan trees following varying chilling periods at 7.2C. The relationship is described by $\log \mathrm{Y}=2.8957-0.0100 \sqrt{\mathrm{X}}$. Regression coefficient is significantly different from zero, $P \leq 0.01$.

Table 2. Association of budbreak in 'Pawnee' and 'Stuart' pecan trees with heat accumulation. ${ }^{\mathrm{Z}}$

\begin{tabular}{|c|c|c|c|}
\hline $\begin{array}{l}\text { Temp } \\
\text { regime }\end{array}$ & $\begin{array}{l}\text { Days to } \\
\text { budbreak } \\
\text { (from 1 Mar.) (1 }\end{array}$ & $\begin{array}{l}\text { Heating degree } \\
\text { days } \\
\text { Feb. to budbreak) }\end{array}$ & $\begin{array}{c}\text { Chilling degree } \\
\text { days } \\
\text { (1 Dec.-February) }\end{array}$ \\
\hline Greenhouse & 20 & 238 & 137 \\
\hline Field & 27 & 235 & 137 \\
\hline
\end{tabular}

${ }^{\mathrm{z}}$ Budbreak was significantly affected by temperature regime. Cultivar effect and cultivar $\times$ temperature regime were not significant; $P \leq$ 0.01 .

${ }^{\mathrm{y}}$ Greenhouse $=$ trees maintained in the greenhouse from 16 Mar. until after budbreak; field = tree maintained in field continuously.

${ }^{\mathrm{x}}$ Base $7.2 \mathrm{C}$.

Table 3. Relationship of heating degree days from 1 Feb. to budbreak of pecan trees $(\mathrm{Y})$ with chilling degree days in December-February $(\mathrm{X})^{\mathrm{z}}$

\begin{tabular}{cccc}
\hline $\begin{array}{c}\text { Base temp } \\
\left({ }^{\circ} \mathrm{C}\right)\end{array}$ & \multicolumn{1}{c}{ Equation $^{\mathrm{y}}$} & SEE & $r^{2}$ \\
\hline 2.2 & $\log \mathrm{Y}=2.7769-0.0143 \sqrt{\mathrm{X}}$ & 0.0701 & 0.627 \\
2.8 & $\log \mathrm{Y}=2.7638-0.0143 \sqrt{\mathrm{X}}$ & 0.0560 & 0.780 \\
3.3 & $\log \mathrm{Y}=2.7401-0.0143 \sqrt{\mathrm{X}}$ & 0.0548 & 0.801 \\
3.9 & $\log \mathrm{Y}=2.7277-0.0147 \sqrt{\mathrm{X}}$ & 0.0540 & 0.821 \\
4.4 & $\log \mathrm{Y}=2.7101-0.0151 \sqrt{\mathrm{X}}$ & $\mathbf{0 . 0 5 3 7}$ & 0.836 \\
5.0 & $\log \mathrm{Y}=2.6922-0.0155 \sqrt{\mathrm{X}}$ & 0.0545 & 0.845 \\
5.6 & $\log \mathrm{Y}=2.6788-0.0158 \sqrt{\mathrm{X}}$ & $\mathbf{0 . 0 5 5 6}$ & 0.851 \\
6.1 & $\log \mathrm{Y}=2.6529-0.0162 \sqrt{\mathrm{X}}$ & 0.0576 & 0.853 \\
6.7 & $\log \mathrm{Y}=2.6317-0.0165 \sqrt{\mathrm{X}}$ & 0.0602 & 0.851 \\
7.2 & $\log \mathrm{Y}=2.6097-0.0120 \sqrt{\mathrm{X}}$ & 0.0640 & 0.848 \\
\hline
\end{tabular}

${ }^{\mathrm{z}}$ Relationship based on data (22 observations) from nine geographical locations with 1 to 6 years of budbreak data per location (see text).

${ }^{y}$ Regression coefficients are significantly different from zero, $P \leq$ 0.05 .

(Table 4). As daily minimum temperature for heat calculation was increased from -1.7 to $4.4 \mathrm{C}$, precision increased up to at least $2.2 \mathrm{C}$. The increase in precision and maximization up to at 
Table 4. Correlation of heating degree days from 1 Feb. to budbreak of pecan trees with chilling degree days in December, January, and February. ${ }^{\mathrm{Z}}$

\begin{tabular}{|c|c|c|c|c|c|c|c|c|c|c|c|c|}
\hline \multirow{2}{*}{$\begin{array}{l}\text { Chilling and } \\
\text { heating base } \\
\left({ }^{\circ} \mathrm{C}\right)\end{array}$} & \multicolumn{12}{|c|}{ Daily minimum temp $\left({ }^{\circ} \mathrm{C}\right)$ used for heat accumulation } \\
\hline & -1.7 & -1.1 & -0.6 & 0 & 0.6 & 1.1 & 1.7 & 2.2 & 2.8 & 3.3 & 3.9 & 4.4 \\
\hline & \multicolumn{12}{|c|}{$r^{2}$} \\
\hline 2.2 & 0.712 & 0.722 & 0.737 & 0.751 & 0.752 & 0.735 & 0.751 & 0.803 & 0.848 & 0.867 & 0.869 & 0.854 \\
\hline 2.8 & 0.827 & 0.839 & 0.857 & 0.867 & 0.883 & 0.882 & 0.894 & 0.915 & 0.915 & 0.922 & 0.935 & 0.897 \\
\hline 3.3 & 0.837 & 0.847 & 0.864 & 0.876 & 0.893 & 0.889 & 0.903 & 0.922 & 0.922 & 0.923 & 0.932 & 0.896 \\
\hline 3.9 & 0.850 & 0.858 & 0.874 & 0.885 & 0.899 & 0.895 & 0.907 & 0.924 & 0.922 & 0.916 & 0.921 & 0.891 \\
\hline 4.4 & 0.854 & 0.863 & 0.878 & 0.886 & 0.899 & 0.896 & 0.905 & 0.923 & 0.919 & 0.911 & 0.914 & 0.872 \\
\hline 5.0 & 0.858 & 0.866 & 0.880 & 0.888 & 0.898 & 0.894 & 0.904 & 0.920 & 0.915 & 0.905 & 0.903 & 0.880 \\
\hline 5.6 & 0.861 & 0.868 & 0.880 & 0.889 & 0.899 & 0.896 & 0.905 & 0.918 & 0.907 & 0.897 & 0.894 & 0.851 \\
\hline 6.1 & 0.860 & 0.866 & 0.877 & 0.884 & 0.893 & 0.891 & 0.901 & 0.910 & 0.901 & 0.883 & 0.877 & 0.832 \\
\hline 6.7 & 0.856 & 0.862 & 0.871 & 0.877 & 0.885 & 0.884 & 0.893 & 0.900 & 0.886 & 0.869 & 0.862 & 0.816 \\
\hline 7.2 & 0.851 & 0.857 & 0.864 & 0.869 & 0.872 & 0.868 & 0.875 & 0.885 & 0.872 & 0.855 & 0.846 & 0.800 \\
\hline
\end{tabular}

least $2.2 \mathrm{C}$ occurred irrespective of base temperature, indicating that heating efficiency decreases with daily minima $<2.2 \mathrm{C}$. When the daily minimum was $2.2 \mathrm{C}$, maximum precision occurred at base temperatures 3.9 to $4.4 \mathrm{C}$ and decreased with higher and lower bases. Except for base $2.2 \mathrm{C}$, the traditional base of $7.2 \mathrm{C}$ gave the poorest precision.

Base temperatures of 2.2, 2.8, and 3.3C differed from other bases in that maximum precision occurred when daily minimum heating temperature was $3.9 \mathrm{C}$ rather than $2.2 \mathrm{C}$ (Table 4). Also, several base and daily minimum heating temperature combinations gave similar $r^{2}$ values of 0.90 to 0.93 . The best relationship between heating and chilling was determined among the highly correlated combinations in Table 4 by comparing their SEE (Table 5). Except for base 2.2C, the SEE was lowest when the daily minimum heating temperature was $2.2 \mathrm{C}$. Among bases, 3.9C produced the lowest SEE. Thus, the best combination for predicting the number of heating degree days for budbreak is base $3.9 \mathrm{C}$ with a daily minimum heating temperature of $2.2 \mathrm{C}$.

The relationship between heat accumulation to budbreak and

Table 5. SEE for the relationship of heating degree days from 1 Feb. to budbreak of pecan trees with chilling degree days in December, January, and February. ${ }^{\mathrm{Z}}$

\begin{tabular}{cccccc}
\hline \hline $\begin{array}{c}\text { Chilling and } \\
\text { heating base } \\
\left({ }^{\circ} \mathrm{C}\right)\end{array}$ & \multicolumn{5}{c}{ Daily minimum temp $\left({ }^{\circ} \mathrm{C}\right)$ used for heat accumulation } \\
\cline { 3 - 6 } & 1.7 & 2.2 & 2.8 & 3.3 & 3.9 \\
\hline & & \multicolumn{5}{c}{$S E E$} \\
2.2 & 0.0839 & 0.0779 & 0.0737 & 0.0752 & 0.0821 \\
2.8 & 0.0554 & 0.0515 & 0.0553 & 0.0581 & 0.0572 \\
3.3 & 0.0529 & 0.0493 & 0.0525 & 0.0572 & 0.0586 \\
3.9 & 0.0519 & 0.0488 & 0.0526 & 0.0603 & 0.0635 \\
4.4 & 0.0539 & 0.0503 & 0.0547 & 0.0633 & 0.0677 \\
5.0 & 0.0548 & 0.0516 & 0.0566 & 0.0658 & 0.0721 \\
5.6 & 0.0542 & 0.0523 & 0.0587 & 0.0682 & 0.0744 \\
6.1 & 0.0564 & 0.0556 & 0.0608 & 0.0730 & 0.0803 \\
6.7 & 0.0596 & 0.0593 & 0.0668 & 0.0780 & 0.0857 \\
7.2 & 0.0658 & 0.0648 & 0.0716 & 0.0828 & 0.0913 \\
\hline
\end{tabular}

${ }^{\mathrm{z}} \mathrm{SEE}$ are for the relationship between heating degree days to budbreak (Y) and chilling degree days $(\mathrm{X})$ as described by $\log \mathrm{Y}=\mathrm{a}-\mathrm{b} \sqrt{\mathrm{X}}$, $P \leq 0.01$

${ }^{\mathrm{y}}$ Chilling was calculated with all daily minimum chilling temperature included; heating was calculated by iterative deletion of minimum daily temperature. chilling is plotted for base 3.9C (Fig. 3). The relationship is plotted with all daily minimum heating temperatures included (Fig. 3A) and for days with minimum heating temperatures below 2.2C excluded (Fig. 3B). Elimination of days with a minimum heating temperature below $2.2 \mathrm{C}$ improved the relationship (Fig, 3, B vs. A). The difference in heating degree days in Fig. 3 A vs. B is inefficient heating. This inefficient heating was positively correlated with chilling degree days (Fig. 4), indicating that cold winters have more inefficient heat than do warm winters. However, the relationship was low $\left(r^{2}=0.313\right)$, which was largely due to the high variability in inefficient heat associated with mild to moderate winters.

Although inefficient heating temperatures can occur (Fig. 4), inefficient chilling temperatures do not appear to be a factor. Iterative deletion of days with minimum chilling temperatures of $-21 \mathrm{C}$ and above did not improve the relationship between heat accumulation to budbreak and chilling. Instead, the precision of the relationship in Fig. 3B gradually decreased as minimum temperatures higher than - 13C were excluded (data not presented).

In contrast to the response of average budbreak date to chilling (Fig. 3), uniformity of budbreak was governed by a critical chilling requirement (Fig. 5). Variation in budbreak increased dramatically with fewer than $\approx 100$ chilling degree days but was low and decreased only slightly with more than $\approx 100$ chilling degree days.

\section{Discussion}

Pecan budbreak does not have a critical requirement for either chilling or heating and, instead, is under the interactive control of heating and chilling. At a given chill accumulation, budbreak has a heat requirement that decreases with chill accumulation. Budbreak may occur without chilling if sufficient heat accumulates. Once chilling is completed, the heat requirement is set. Subsequent date of budbreak will vary depending on the rate at which heat accumulates following completion of chilling. A similar mechanism is apparent in pecan seed germination. Chilling greatly enhances seed germination, but lack of chilling does not prevent germination (Sparks et al., 1974; Van Staden et al., 1976; Wolstenholme, 1974). As with budbreak (Figs. 2 and 3), heat required for nut germination decreases with chill 


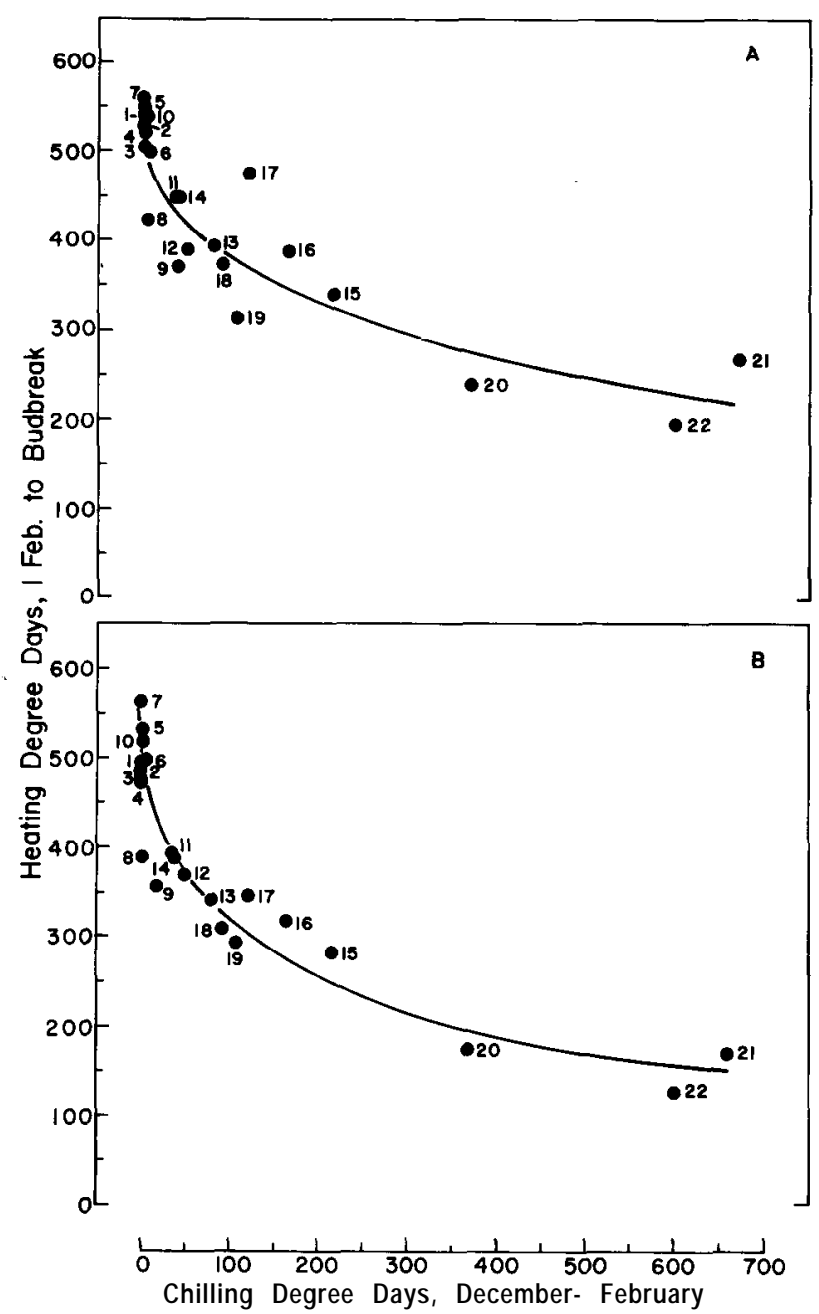

Fig. 3. Relationship of heat accumulation from 1 Feb. to budbreak of pecan trees with chill accumulation in December, January, and February. Chilling and heating degree days were calculated from base 3.9C. (A) All daily minimum heating temperatures included; (B) minimum daily heating temperatures $<2.2 \mathrm{C}$ excluded. A) The relationship is described by $\log \mathrm{Y}=2.7277-0.0147 \sqrt{\mathrm{X}}, r^{2}=$ 0.821. (B) The relationship is described by $\log \mathrm{Y}=2.7190-$ $0.0216 \sqrt{\mathrm{X}}, r^{2}=0.923$. Regression coefficients are significantly different from zero $(\mathrm{P} \leq 0.01)$. Numbers within figure designate location and year: 1-4 = Roodeplaat, South Africa, 1981-84; 510 = Visalia, Calif., 1982-86, 1988; 11 = Griffin, Ga., 1916; 12 $14=$ Watkinsville, Ga., 1989-91; 15 and $16=$ Stillwater, Okla., 1972 and 1976; 17 = Sparks, Okla., 1976; $18=$ Shreveport, La., 1977; 19 = Stoneville, Miss., 1986; and 20-22 = Lincoln, Neb., 1987-89.

accumulation, and, at a given chill level, germination date varies with rate of heat accumulation (Wolstenholme, 1974).

Variability in pecan budbreak, unlike time of budbreak, has a critical chilling requirement and is not under the interactive control of heating and chilling. Thus, the problem with insufficient chilling in pecan is not lack of budbreak but is one of uniformity of the event. The problem is the same with pecan seed germination (Sparks et al., 1974). Because the chilling requirement of $\approx 100$ degree days (Fig. 5) is based on variation among cultivars, the value for uniform budbreak within a cultivar is expected to vary from 100 depending on cultivar. Similarly, because the relationship between heat required for budbreak date and chilling (Fig. 3B) is based on an average of cultivars,

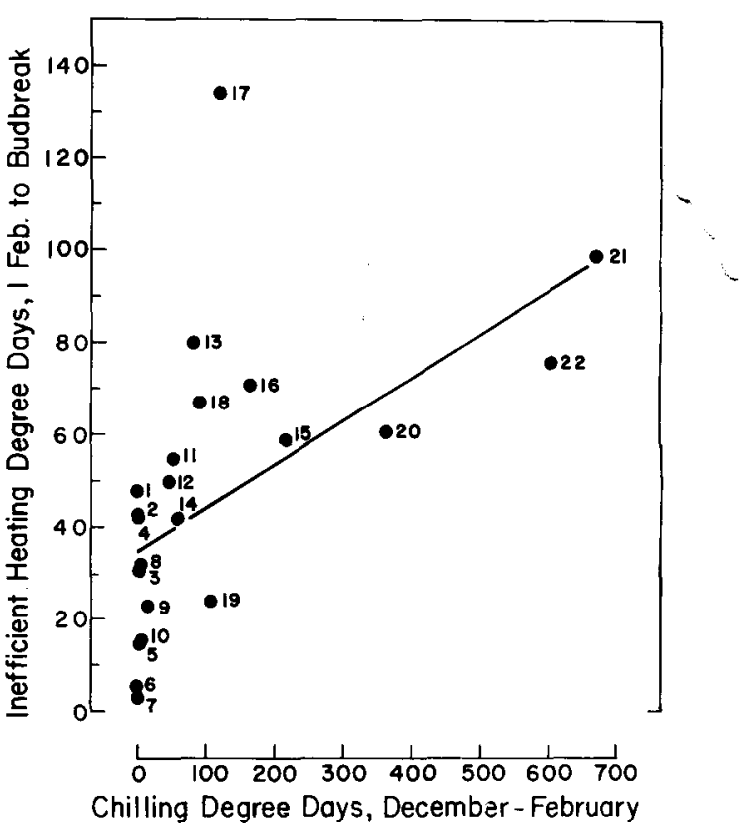

Fig. 4. Inefficient heating degree days as a function of chilling. Chill and heat accumulation were calculated from base 3.9C. The relationship is described by $\mathrm{Y}=35.16-0.0940 \mathrm{X}$. Regression coefficient is significantly different from zero, $P \leq 0.01$. Numbers within figure designate location and year (see legend for Fig. 3).

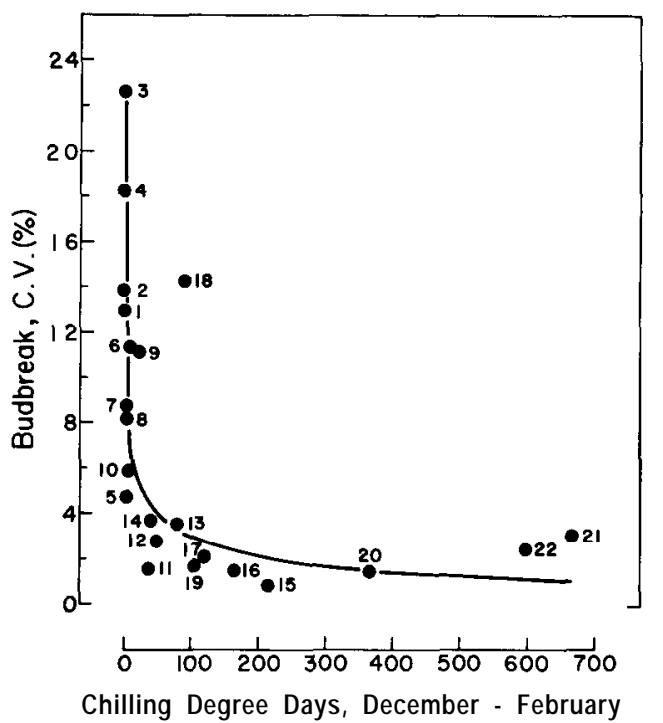

Fig. 5. Variation in budbreak among pecan cultivars as a function of chilling during December, January, and February. Chilling degree days were calculated from base 3.9C. Numbers within figure designate location and year (see legend for Fig. 3). The relationship is described by $\bar{Y}=3.3941-0.8305$ Log X. Regression coefficient is significantly different from zero, $P \leq 0.01$. Observation no. 18 is excluded from the equation.

heating and chilling values for an individual cultivar may vary from the regression line.

The origin of the concept that pecan and other tree species have a definitive chilling requirement developed from the use of stem cuttings in studying chilling, in sufficient attention to the heat effect on budbreak, and from the method of evaluating chilling response. Cuttings, due to their limited viability, dictate a short-term experiment. Use of cuttings does not allow sufficient time for adequate evaluation. Valid conclusions are more 
likely by use of rooted trees in a long-term study. For pecan, the risk of using stem cuttings (Amling and Amling, 1980; McEachern et al., 1978) vs. rooted trees is evident by comparing these workers' results with those in Figs. 1 and 3. Similarly, in peach, Weinberger (1950a) concluded that leaf buds of 'Redhaven' have a chilling requirement of $950 \mathrm{~h}$ at $7.2 \mathrm{C}$; whereas time of budbreak of terminal buds on own-rooted 'Redhaven' trees was advanced up to at least $2040 \mathrm{~h}$ of chilling (Scalabrelli and Couvillon, 1986). The importance of the method of evaluating chilling response is also evident in the latter's work. When response ( $\geq 90 \%$ of buds broken) was based on chilling hours alone, terminal buds appeared to have a chilling requirement of $600 \mathrm{~h}$ and the requirement was completed; however, when evaluated on the basis of minimum heat required to reach $90 \%$ budbreak, the chilling requirement is $\geq 2040 \mathrm{~h}$.

The data indicate that within the normal range of chilling received in nature, chilling, and thus rest, is rarely if ever "completed." Incompletion of chilling is indicated by the response shown in Fig. 1, by the relationship illustrated in Fig. 3, and by the supporting mathematical relationship, $\log \mathrm{Y}=\mathrm{a}-$ b $\sqrt{X}$, between heat accumulation and chilling. The mathematical relationship between heat accumulation to budbreak and chill accumulation implies that if chilling were completed, budbreak would occur with very low heat. In this regard; potted pecan seedlings were observed to break their buds in cold storage when kept for several months at 7.2C. Similarly, G.A. Couvillon (personal communication) observed the same response with peach trees kept in prolonged storage at 7.2C. Lack of rest completion in peach is also supported by experimental data (Wolak and Couvillon, 1976). These workers found that application of either thiourea- $\mathrm{KNO}_{3}$ or $\mathrm{GA}_{3}$ reduced growing degree days required for budbreak, even though application was made 1 week following "rest completion." They correctly proposed that quiescent buds remain under a rest influence.

The regulation of budbreak by chilling and heating (Fig. 3B) has significant implications. If chill accumulation is high in the winter, much less heat is required for budbreak than when chill accumulation is low. This inverse relationship allows pecans to grow under a wide range of climatic conditions. In regions with cold winters, e.g., Nebraska, the high chilling received in the winter enables buds to break with minimum heating in the springtime. Growth commences within minimum time, thus increasing the possibility that the vegetative and fruiting cycles will be completed within the short growing season associated with cold winters. On the other extreme, the lack of an obligate chilling requirement allows pecan to be grown in regions with little or no chilling, e.g., Brazil, California, Israel, south Texas, and South Africa. Budbreak regulation by heating and chilling is an apparent adaptive survival mechanism resulting in pecan being native over a wide geographic and thus wide climatic range within the United States from south Texas to Iowa. The apparent decreasing efficiency of minimum heating temperatures $<2.2 \mathrm{C}$ may also be an adaptive survival mechanism. The less-sensitive response to lower heating temperatures delays budbreak and minimizes the chance of damage from late spring freezes.

In regions with mild winters, commercial problems can arise from budbreak regulation by heating and chilling. If chilling is high and heat accumulation is rapid, budbreak occurs in minimum time, increasing the period of exposure to late spring freezes. If chilling is low but heating is exceptionally high and rapidly accumulated, budbreak is also advanced. The latter situation occurred in 1955. Budbreak was advanced by $\approx 3$ weeks and the crop was subsequently destroyed by a late spring freeze on 23 Mar. (Hagler, 1955). If the winter is warm and the spring is cool, budbreak of pecan cultivars that have a relatively high heating and/or chilling requirement will be delayed. Further, because springtime heat determines time of nut maturity (Sparks, 1989), nut maturity in these cultivars will be correspondingly delayed, as with 'Stuart' pecan in Georgia in 1989. Also, in pecan regions with little or no chilling (Brazil, California, Israel, south Texas, and South Africa) variation in budbreak (Fig. 5) both among and within cultivars is a problem because of staggered nut maturity. However, in these regions, nut yields are as high as or higher than similar cultivars grown in areas with cooler winters. Similarly, observations show that the highchill-requiring 'Stuart' pecan (Amling and Amling, 1980; McEachern et al., 1978), breaks buds exceptionally late but fruits heavily in the warm winter area of Crystal City and Eagle Pass, Texas. Thus, the chilling effect in pecan appears to be on budbreak and not on pistillate flower formation. The often-proposed effect of low chilling on pecan yields may be more from extrapolation from peach than from fact. In peach, the effect of inadequate chilling on fruit yields is normally due to flower bud abortion rather than a direct effect on flower initiation and development (Weinberger, 1950b). In pecan, the reproductive bud is mixed (Wetzstein and Sparks, 1984) and bud abortion does not occur following low chilling (Finch and Van Horn, 1939).

The relationship of heating accumulation to budbreak with chilling (Fig. 3B) is very close, especially considering that budbreak was recorded by different observers over a wide range of years and geographic regions, that cultivars were not the same among locations, and that temperature was recorded at varying distances from and probably at elevations different from the orchards. This model predicts average budbreak date among pecan cultivars growing over a wide climatic range and is not restricted by conditions imposed by geographic location, as with the Utah Model (Richardson et al., 1974, 1975). In the model (Fig. 3B), the largest deviations from the regression line occurred with data from Oklahoma in all years and from California in 1988 and 1989. The deviations in California may have been due to longer-than-normal fog cover, which would underestimate chilling due to abnormally low bud temperatures (Weldon, 1934). Conversely, in Oklahoma, clear sky conditions may have abnormally increased bud temperature, in which case ambient temperatures would overestimate chilling. The model was not improved by iterative deletion of low chilling temperatures. Erez and Couvillon (1987) found that chilling efficiency decreased from 8 to $0 \mathrm{C}$ if chilling was constant but not if chilling was interspersed with higher temperatures. Apparently, the promotive effect of interspersion continues to be operative at temperatures $<0 \mathrm{C}$. The substantial improvement in the model by deleting days with a minimum heating temperature $<2.2 \mathrm{C}$ (Fig. 3, B vs. A) needs verification.

Data for own-rooted peaches (Scalabrelli and Couvillon, 1986) suggest that budbreak in this tree, and probably other deciduous trees, is also under the interactive control of heating and chilling. Although Scalabrelli and Couvillon's data were analyzed by mean separation, the relationship between heat required for peach budbreak and chilling hours appears to also follow Log $\mathrm{Y}=\mathrm{a}-\mathrm{b} \sqrt{\mathrm{X}}$ and especially if response to the unchilled treatment could have been included. However, in the case of cultivars with a very high chilling requirement, the dependence of budbreak on the interactive effect of heating and chilling has more theoretical interest than practical value. For example, highchill peach cultivars in the coastal regions of southern California 
will break buds without chilling once sufficient heat accumulates; but budbreak may be as late as July or August (Smith, 1907).

In summary, pecan budbreak is under the interactive control of both heating and chilling. The heat requirement decreases with chill accumulation, and, once sufficient heat accumulates, budbreak will occur with no chilling. In contrast to budbreak, variability in budbreak has a critical chilling requirement.

\section{Literature Cited}

Amling, H.J. and K.A. Amling. 1980. Onset, intensity, and dissipation of rest in several pecan cultivars. J. Amer. Soc. Hort. Sci. 105:536540.

Amling, H.J. and K.A. Amling. 1983. Physiological differentiation of pistillate flowers of pecan and cold requirements for their initiation. J. Amer. Soc. Hort. Sci. 108:195-198.

Arnold, C.E. 1971. Pecans in central and south Florida. Proc. Fla. State Hort. Sci. 84:345-350.

Boethel, D.J., W.G. Grovenberg, R.D. Eikenbary, and R.W. McNew. 1976. Infestation levels of pecan leaf phylloxera, Phylloxera notabilis Pergande, on pecan cultivars. J. Econ. Entomol. 69:637-639.

Burke, J.A. and H.A. Hinrichs. 1976. Pecan development from budbreak through pollination for 57 varieties in 1976. Proc. Okla. Pecan Growers Assn. 46:21-25.

Couvillon, G.A. and A. Erez. 1985. Effect of level and duration of high temperatures on rest in the peach. J. Amer. Soc. Hort. Sci. 110:579-581.

Erez, A. and G.A. Couvillon. 1987. Characterization of the influence of moderate temperatures on rest completion in peach. J. Amer. Soc. Hort. Sci. 112:677-680.

Erez, A., G.A. Couvillon, and C.H. Hendershott. 1979a. Quantitative chilling enhancement and negation in peach buds by high temperatures in a daily cycle. J. Amer. Soc. Hort. Sci. 104:536-540.

Erez, A., G.A. Couvillon, and C.H. Hendershott. 1979b. The effect of cycle length on chilling negation by high temperatures in dormant peach leaf buds. J. Amer. Soc. Hort. Sci. 104:573-576.

Finch, A.H. and C.W. Van Horn. 1939. Notes on the relation of warm winter temperatures to blossoming and nut setting of the pecan. Proc. Amer. Soc. Hort. Sci. 37:493-497.

Gammon, N., Jr. and W.B. Sherman. 1972. Bud development evaluation. Pecan Quart. 6(4):11.

Gustafson, W.A. and T.A. Morrissey. 1989. Northern pecan research 1989-Budbreak, flowering and fruiting data for 38 pecan clones/ cultivars. Annu. Rpt. Northern Nut Growers Assn. 80:90-92.

Hagler, T.N. 1956. Freeze injury to pecans in Alabama. Proc. Southeastern Pecan Growers Assn. 49:9.

Haulik, T.K. and L.C. Holtzhausen. 1987. Evaluation of five pecan cultivars [Carya illinoensis (Wang.) K. Koch] for yield, precocity, alternate bearing, leaf:nut ratio and length of growing season in the Transvaal middleveld. S. Afr. J. Plant Soil 4:70-74.

McEachern, G.R., N.B. Wolstenholme, and J.B. Storey. 1978. Chilling requirement of three pecan cultivars. HortScience 13:694.

Nelson, R.O., W.A. Gustafson, and T.M. Morrissey. 1987. Northern pecan research-budbreak, flowering, and fruiting data for 16 pecan clones. Annu. Rpt. Northern Nut Growers Assn. 78:117-118.

Nelson, R.O., W.A. Gustafson, and T.M. Morrissey. 1988. Northern pecan research 1988-budbreak, flowering and fruiting data for 31 pecan clones. Annu. Rpt. Northern Nut Growers Assn. 79:70-72.

O'Barr, R.D. and S. Rachal. 1987. Louisiana pecan variety update. Pecan South 2(4):12-16, 27, 28.

Richardson, E.A., S.D. Seeley, and D.R. Walker. 1974. A model for estimating the completion of rest for 'Redhaven' and 'Elberta' peach trees. HortScience 9:331-332.

Richardson, E.A., S.D. Seeley, D.R. Walker, J.L. Anderson, and G.L. Ashcroft. 1975. Pheno-climatography of spring peach bud development. HortScience 10:236-237.

Romberg, L.D. 1944. Some characteristics of the juvenile and bearing pecan tree. Proc. Amer. Soc. Hort. Sci. 44:225-259.

Scalabrelli, G. and G.A. Couvillon. 1986. The effect of temperature and bud type on rest completion and the $\mathrm{GDH}^{\circ} \mathrm{C}$ requirement for budbreak in 'Redhaven' peach. J. Amer. Soc. Hort. Sci. 111:537540.

Sibbett, G.S., T.E. Thompson, and N. Troiani. 1988. Pecans for California. Pecan South 22(3):16-21.

Smith, R.E. 1907. Report of the pathologist. Calif. Agr. Expt. Sta. Rpt. 1907:221-256.

Sparks, D. 1989. Predicting nut maturity of the pecan from heat units. HortScience 24:454-455.

Sparks, D. and J.W. Chapman. 1970. The effect of indole-3-butyric acid on rooting and survival of air-layered branches of the pecan, Carya illinoensis Koch., cv. 'Stuart'. HortScience 5:445-446.

Sparks, D., J.W. Chapman, and D.W. Lockwood. 1974. Stratification promotes germination. Pecan Quart. 8(1):13.

Stuckey, H.P. 1916. The two groups of varieties of the Hicoria pecan and their relation to self-sterility. Ga. Expt. Sta. Bul. 124.

Van Staden, J., B.N. Wolstenholme, and G.G. Dimalla. 1976. Effect of temperature on pecan seed germination. HortScience 11:261-262.

Waite, M.B. 1925. Factors influencing the setting of nuts and fruits. Proc. Natl. Pecan Growers Assn. 24:122-144.

Weinberger, J.H. 1950a. Chilling requirements of peach varieties. Proc. Amer. Soc. Hort. Sci. 56:122-128.

Weinberger, J.H. 1950b. Prolonged dormancy of peaches. Proc. Amer. Soc. Hort. Sci. 56:129-133.

Weldon, G.P. 1934. Fifteen years study of delayed foliation of deciduous fruit trees in southern California. Monthly Bul. Calif. Dept. Agr. July-Sept. 23:7-9.

Wetzstein, H.Y. and D. Sparks. 1983. Morphology of pistillate flower differentiation in pecan (Carya illinoensis). J. Amer. Soc. Hort. Sci. 108:997-1003.

Wetzstein, H.Y. and D. Sparks. 1984. The morphology of staminate flower differentiation in pecan. J. Amer. Soc. Hort. Sci. 245-252.

Wolak, R.J. and G.A. Couvillon. 1976. Time of thiourea- $\mathrm{KNO}_{3}$ application on the rest requirement and bud development in 'Loring' peach. HortScience 11:400-402.

Wolstenholme, B.N. 1970. Patterns of budbreak in a pecan cultivar/ cultural experiment under dryland conditions. Agroplantae 2:61-66.

Wolstenholme, B.N. 1974. Effect of stratification and temperature on germination of pecan nuts. Citrus and Sub-trop. Fruit J. (Sept.), 9, $10,20$. 